\title{
Effect of particle size and lattice strain on Debye-Waller factors of $\mathrm{Fe}_{3} \mathrm{C}$ nanoparticles
}

\author{
E PURUSHOTHAM* and N GOPI KRISHNA ${ }^{\dagger}$ \\ Department of Physics, SR Engineering College (Autonomous), Warangal 506 371, India \\ ${ }^{\dagger}$ Department of Physics, Kakatiya University, Warangal 506 009, India
}

MS received 13 February 2013; revised 30 May 2013

\begin{abstract}
Fe}_{3} \mathrm{C}$ nanoparticle powders have been prepared by a high energized ball mill. The resulting nanoparticle powders were characterized by X-ray diffraction (XRD) and scanning electron microscopy (SEM) measurements. The high-energy ball milling of $\mathrm{Fe}_{3} \mathrm{C}$ after $10 \mathrm{~h}$ resulted in crystalline size of about $5 \mathrm{~nm}$. The Debye temperature, mean-square amplitudes of vibration, Debye-Waller factor, lattice parameters, particle size, lattice strain and vacancy formation of energies of $\mathrm{Fe}_{3} \mathrm{C}$ nanoparticles prepared by ball mill have been obtained from $X$-ray integrated intensities. The integrated intensities have been measured with a Philips CWU $3710 \mathrm{X}$-ray powder diffractometer fitted with a scintillation counter using filtered $\mathrm{CuK} \alpha$ radiation at room temperature and have been corrected for thermal diffuse scattering. The $\mathrm{X}$-ray Debye temperatures obtained in the present investigation has been used to estimate the vacancy formation energies for $\mathrm{Fe}_{3} \mathrm{C}$ nanoparticles.
\end{abstract}

Keywords. Nanocrystalline $\mathrm{Fe}_{3} \mathrm{C}$ ball milling; XRD; SEM; lattice parameters; particle size; lattice strain, Debye-Waller factor; vacancy formation energy.

\section{Introduction}

In recent years, synthesis of nanoparticles is a subject of intensive research, because of their basic scientific interest as well as for the technological importance. The nanoparticles exhibit very interesting properties like electrical, optical, magnetic, chemical, etc and which could not be achieved by their bulk nanoparticles (Colvin et al 1994). Nanomaterials may also be used in various technological applications like medical imaging, drug targeting, refrigeration system and other biological applications and catalysis (Kesavan et al 1999).

Recently, chemists, physicists and material scientists have shown great interest in the development of new methods for the synthesis of nanomaterials. These materials are important for further miniaturization of electric devices, nanofluids (Abid et al 2001) enhance efficiency of heat engines, as chemical catalysts (Eastman et al 2001; Darugar et al 2006) and lasing materials (Fujiwara et al 1999). Physical and chemical properties of these materials are highly size-dependent. Therefore, it is important to develop novel techniques for the synthesis of nanomaterials.

Metal carbides are generally referred to as refractory materials due to their high melting temperatures and high hardness and are being used as cutting tools, wear-resistance parts and surface coating. They deform

*Author for correspondence (psm45456@gmail.com) plastically in a manner similar to $f c c$ metals and become relatively soft and ductile at high temperatures. Because of their high chemical stability, high Young's modulus at high temperatures, good thermal shock resistance and thermal conductivity, metal carbides are also being used as structural materials (Caer and Matteazzi 1991). Usually, metal carbides are prepared by conventional ceramic route, which requires a very high temperature as well as good vacuum condition or ultra pure inert gas atmosphere. However, nanocrystalline metal carbides with homogeneous composition can be prepared at room temperature by mechanical alloying (MA), the stoichiometric mixture of elemental powders under inert atmosphere.

Mechanical alloying process is a very useful solid-state technique for fabrication of nanocrystalline structure with improved properties (Tanaka 1992; Calka 1993; Suryanarayana 2001). If the $\mathrm{Fe}-\mathrm{C}$ system is composed of a very fine microstructure, which can be synthesized by MA, it is possible to produce an advanced material with high hardness, wear resistance, toughness and good magnetic properties.

The formation of $\mathrm{Fe}_{3} \mathrm{C}$ carbide and some hexagonal carbides (Caer and Matteazzi 1991; Nadutov et al 2000; Shabashov et al 2001), formation of $\mathrm{Fe}_{3} \mathrm{C}$ only (Caer et al 1990a, b) and formation of $\mathrm{Fe}_{3} \mathrm{C}$ carbide (Tokumitsu 1997; Tokumitsu and Memoto 2001) have been reported earlier. For the mixtures with $x=20-25 \%$, in all the above cases, $\mathrm{Fe}_{3} \mathrm{C}$ phase was obtained after a long period of milling with significant amount of $\mathrm{Fe}$ as an un-reacted powder and in none of the cases microstructures of the ball-milled samples 
were characterized in terms of lattice strain imperfections related to physical properties of the prepared materials.

The objectives of the present work are: (i) to produce nanocrystalline $\mathrm{Fe}_{3} \mathrm{C}$ by high-energy ball milling of $\mathrm{Fe}$ and $\mathrm{C}$ (graphite) powders at room temperature and (ii) to calculate particle size, effect of lattice strain on the DebyeWaller factor. Ball-milled samples are related to several microstructure parameters like change in particle size, lattice strain and the effect of lattice strain on the DebyeWaller factor. All these microstructure parameters can be estimated quantitatively by analysing XRD patterns of ballmilled samples employing either of the Hall-Williamson's method, as the XRD pattern of $\mathrm{Fe}_{3} \mathrm{C}$ phase (orthorhombic) is composed of several overlapping reflections.

TEM is one of the powerful techniques for crystallite size measurement, but it has certain limitations. Since TEM images represent only a local region, many samples and images are required to provide average information for the entire sample. Not only this, the TEM sample preparation method is an involved and time consuming one. XRD technique is free from these limitations. $\mathrm{X}$-ray diffraction is, on the other hand, a simple and easier approach for determination of crystallite size of powder samples.

The Debye-Waller factor is an important lattice dynamical property. There is considerable $\mathrm{X}$-ray work on the Debye-Waller factors of $\mathrm{Fe}_{3} \mathrm{C}$. But it is interesting to study the effect of particle size and lattice strains on the Debye-Waller factors of these metals. Pradhan et al (2009) studied the microstructure characterization of nanocrystalline $\mathrm{Fe}_{3} \mathrm{C}$ synthesized by high-energy ballmilling. Glushenkov et al (2008) showed reactive ballmilling to produce nanocrystalline $\mathrm{ZnO}$. Inagaki et al (1971, 1973) showed that in several non-metallic powders, the strains produced during grinding have a significant effect on the Debye-Waller factors measured from X-ray diffraction intensities. Sirdeshmukh et al (1993) observed the effect of lattice strains on the Debye-Waller factors in semiconductor powder materials. Gopi Krishna and Sirdeshmukh (1993) studied the effect of lattice strains on the Debye-Waller factor of ytterbium metal. Gopi Krishna et al (2010) studied the effect of lattice strains on the Debye-Waller factor of Mg, Zn and Cd for slow grinding in an agate mortar. In the present investigation, results of a systematic study of the lattice parameters, effect of particle size and lattice strains on the DebyeWaller factors of $\mathrm{Fe}_{3} \mathrm{C}$ metal powder is reported using ball mill. These results are being reported for the first time.

\section{Experimental}

Experimental profiles of un-milled and all ball-milled powders are, therefore, fitted with the simulated powder diffraction patterns generated considering the contribution from the following three phases: (i) $\alpha$-Fe (cubic, space group: $\operatorname{Im} 3 m, a=0.2866 \mathrm{~nm}$ ), (ii) graphite ${ }^{\odot}$ (hex, $a=0.2740 \mathrm{~nm}, \quad c=0.6707 \mathrm{~nm}$, space group: $P 63 / m m c$ ) and (iii) $\mathrm{Fe}_{3} \mathrm{C}$ (orthorhombic, space group: Pnma, $a=$ $0.5091 \mathrm{~nm}, b=0.6743 \mathrm{~nm}, c=0.4526 \mathrm{~nm})$. Highly pure $\alpha$-Fe and graphite rods obtained from the Solid State Physics Laboratory, New Delhi, were was used. The powder samples were obtained by gently filing highly pure $\mathrm{Fe}$ and graphite rods with a jeweller's file and mixed in 3:1 molar ratio of $\mathrm{Fe}$ and $\mathrm{C}$. A part of this powder was used to prepare the initial sample. The remaining powder was subjected to milling in a high-energy planetary ball mill (Model: Retsch, PM 100, Germany) for 2, 4, 6, 8 and $10 \mathrm{~h}$ to produce strains and decrease the particle size in a stainless steel chamber using tungsten carbide and zirconia balls of $10 \mathrm{~mm} \phi$ and $3 \mathrm{~mm} \phi$ ball sizes, respectively.

The un-milled sample $(0 \mathrm{~h})$ is fitted very well with Fe but with preferred orientation of graphite particles along [0 0 2 2]. Graphite reflections disappear within 30 min of milling and peak-broadening of Fe reflections increases continuously with increasing milling time up to $2 \mathrm{~h}$ of milling. This peak-broadening is fitted by considering both the effects of small particle size and lattice strain, which are reasoned due to cold working on Fe lattice during ball-milling.

X-ray diffractograms were recorded with the initial sample and with samples prepared after each spell of milling. The diffractograms were obtained with a Philips CWU $3710 \mathrm{X}$-ray powder diffractometer in the $2 \theta$ range of $20-120^{\circ}$ using filtered $\operatorname{CuK} \alpha$, a goniometer speed of $0.5^{\circ}$ per min and a chart speed of $20 \mathrm{~mm} / \mathrm{min}$. XRD patterns of $\mathrm{Fe}_{3} \mathrm{C}$ are given in figure 1. All measurements were made at room temperature. The observed integrated intensities have been corrected for thermal diffuse scattering using the method of Chipman and Paskin (1959).

\section{Method of analysis}

The procedure for the determination of directional meansquare amplitudes of vibration $\left\langle u_{\|}^{2}\right\rangle$ and $\left\langle u_{\perp}^{2}\right\rangle$ from the

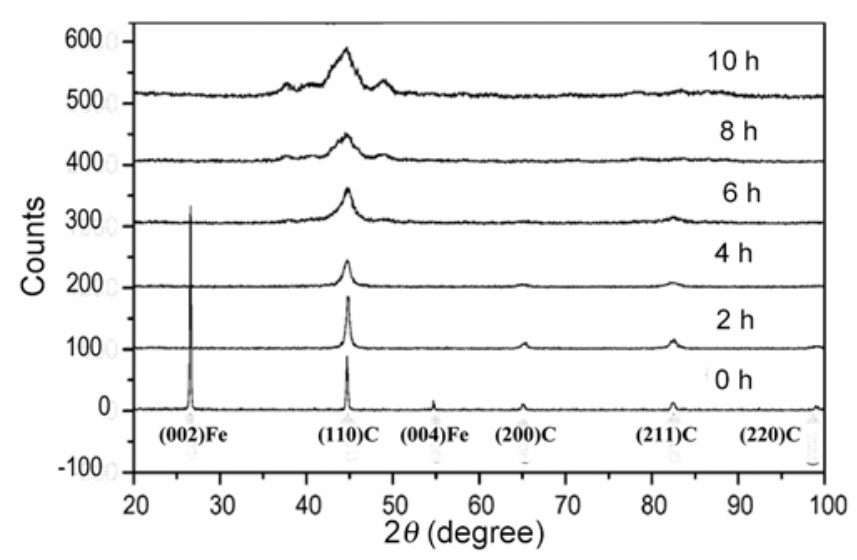

Figure 1. X-ray powder diffraction patterns of $\mathrm{Fe}_{3} \mathrm{C}$. 
intensity data and the estimation of associated errors is as discussed by Gopi Krishna et al (1986). The average mean square amplitude $\left\langle u_{\mathrm{av}}^{2}\right\rangle$ can be obtained from the relation:

$$
\left\langle u_{\mathrm{av}}^{2}\right\rangle=1 / 3\left(\left\langle u_{\|}^{2}\right\rangle+2\left\langle u_{\perp}^{2}\right\rangle\right),
$$

and the directional Debye-Waller factors $B_{\perp}$ and $B_{\|}$were obtained from the equations

$$
\left.\begin{array}{l}
B_{\perp}=8 \pi^{2}\left\langle u_{\perp}^{2}\right\rangle \\
B_{\|}=8 \pi^{2}\left\langle u_{\| \mid}^{2}\right\rangle
\end{array}\right\} .
$$

The mean Debye-Waller factor $B$ is given by

$$
B=\left(2 B_{\perp}+B_{\|}\right) / 3 \text {. }
$$

The directional Debye temperatures $\theta_{\perp}, \theta_{\|}$and mean Debye temperature $\theta_{\mathrm{M}}$ were obtained from $B_{\perp}, B_{\|}$and $B$, respectively using the Debye-Waller theory (James 1967) relation:

$$
\left.\begin{array}{l}
B=\left(6 h^{2} / M k_{\mathrm{B}} \theta_{\mathrm{M}}\right) W(X) \\
B_{\perp}=\left(6 h^{2} / M k_{\mathrm{B}} \theta_{\perp}\right) W(X) \\
B_{\|}=\left(6 h^{2} / M k_{\mathrm{B}} \theta_{\|}\right) W(X)
\end{array}\right\},
$$

where $h$ is the Planck's constant, $k_{\mathrm{B}}$ the Boltzmann constant, $M$ the atomic weight. The function $W(X)$ is given by:

$$
W(X)=[\phi(X) / X+(1 / 4)],
$$

where $X=\theta_{\mathrm{M}} / T, T$ is the temperature of the crystal and $\phi(X)$ the Debye function. The values of $W(X)$ for a wide range of $X$ can be obtained from the International Standard tables (1968).

\subsection{Lattice strain and particle size determination}

When the size of the individual crystals is less than about $100 \mathrm{~nm}$, the term 'particle size' is usually used. When the crystallites of a material are smaller than $100 \mathrm{~nm}$, they have a number of too small parallel diffraction planes and so they produce broadened diffraction peaks instead of a sharp peak. Lattice strain present in the sample is another cause of broadening of Bragg diffraction peaks. In addition to this, there are instrumental factors such as unresolved $\alpha_{1}$ and $\alpha_{2}$ peaks, imperfect focusing which lead to the line broadening. There are various methods in practice to estimate the particle size. X-ray diffraction is a simpler and easier approach for the determination of precise particle size and the lattice strain in powder samples. The principle involved in the X-ray diffraction approach is precise quantification of the broadening of the Bragg diffraction peaks. Scherrer equation, HallWilliamson method and Warren-Averbach method are some of the techniques based on this principle. Of the above methods, Scherrer equation method for the estimation of particle size does not take into account the broadening due to lattice strain present in the sample. As such in the present investigation, the lattice strains have been estimated using Hall-Williamson method. Recently, Bharati et al (2006) used this method to estimate the lattice strain and particle sizes of silver nanoparticles and composite silver nanoparticles. In this method, the integral breadth of the diffraction peak is determined. The integral breadth is given by the integrated intensity divided by the maximum intensity. Thus, the observed peak broadening, $B_{0}$ may be represented as:

$$
B_{\mathrm{o}}=B_{\mathrm{i}}+B_{\mathrm{r}}
$$

where $B_{0}$ is the observed peak broadening in radians, $B_{\mathrm{i}}$ the instrumental broadening in radians and $B_{\mathrm{r}}$ the broadening due to the small particle size and lattice strain. The instrumental broadening has been estimated using a pure strain-free fine sodium chloride powder sample subjected to XRD under identical conditions as those for the strained metallic powders. Equation (5) holds good if the diffraction peaks exhibit purely Cauchy profile. However, when the diffraction peaks are partly Cauchy and partly Gaussian for profiles, the following relation between $B_{0}$, $B_{\mathrm{i}}$ and $B_{\mathrm{r}}$ holds good (Bharati et al 2006)

$$
B_{\mathrm{r}}=\left[\left(B_{\mathrm{o}}-B_{\mathrm{i}}\right)\left(B_{\mathrm{o}}^{2}-B_{\mathrm{i}}^{2}\right)^{1 / 2}\right]^{1 / 2} \text {. }
$$

Now, according to Scherrer equation, the broadening due to small particle size may be expressed as

$$
B_{\mathrm{c}}=\frac{k \lambda}{t} \cos \theta,
$$

where $B_{\mathrm{c}}$ is the broadening solely due to small crystallite size, $K$ a constant whose value depends on particle shape and usually taken as unity, $t$ the crystallite size in nanometers, $\theta$ the Bragg angle and $\lambda$ the wavelength of incident $\mathrm{X}$-ray beam in nanometers.

Similarly, according to Wilson (1949), the broadening due to lattice strain may be expressed by the relation:

$$
B_{\mathrm{s}}=\varepsilon \tan \theta \text {, }
$$

where $B_{\mathrm{s}}$ is the peak broadening due to lattice strain, $\varepsilon$ the strain distribution within the material and $\theta$ the Bragg

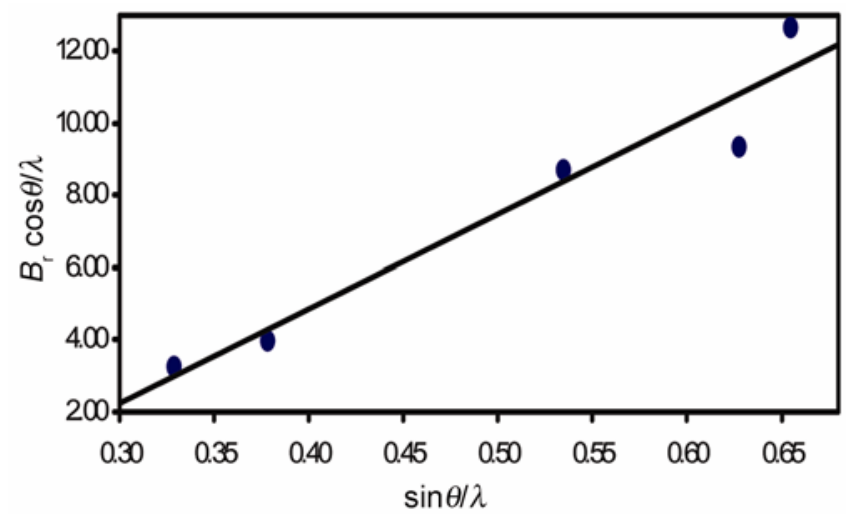

Figure 2. Plot of $B_{\mathrm{r}} \cos \theta / \lambda$ vs $\sin \theta / \lambda$ for $\mathrm{Fe}_{3} \mathrm{C}$ after milling for $8 \mathrm{~h}$. 
Table 1. Values of particle size $(t)$, lattice strain $(\varepsilon)$, mean Debye-Waller factor $(B)$, root mean square amplitudes of vibration $\langle u\rangle$, mean Debye temperature $\left(\theta_{\mathrm{M}}\right)$ and energy of vacancy formation $\left(E_{\mathrm{f}}\right)$ of strained nano $\mathrm{Fe}_{3} \mathrm{C}$ powder.

\begin{tabular}{|c|c|c|c|c|c|c|c|c|c|c|}
\hline Metal & $\begin{array}{l}\text { Milling } \\
\text { time (h) }\end{array}$ & $\varepsilon \times 10^{3}$ & $t(\mathrm{~nm})$ & $a(\mathrm{~nm})$ & $b(\mathrm{~nm})$ & $c(\mathrm{~nm})$ & $\langle u\rangle$ & $B\left(\AA^{2}\right)$ & $\theta_{\mathrm{M}}(\mathrm{K})$ & $E_{\mathrm{f}}(\mathrm{eV})$ \\
\hline$\alpha-\mathrm{Fe}$ & 0 & 0.8225 & $139 \cdot 23$ & $0 \cdot 2866$ & - & - & - & $0 \cdot 36$ & 428 & - \\
\hline $\mathrm{C}$ & 0 & 0.9903 & $192 \cdot 28$ & $0 \cdot 2740$ & - & 0.6707 & - & - & - & - \\
\hline $\mathrm{Fe}_{3} \mathrm{C}$ & 0 & $1 \cdot 1526$ & 198.67 & 0.5091 & 0.6743 & 0.4526 & 0.0063 & $0 \cdot 30$ & 274 & $5 \cdot 86$ \\
\hline $\mathrm{Fe}_{3} \mathrm{C}$ & 2 & 3.4129 & $11 \cdot 12$ & 0.5078 & 0.6792 & 0.4532 & 0.0076 & $0 \cdot 46$ & 223 & $3 \cdot 74$ \\
\hline $\mathrm{Fe}_{3} \mathrm{C}$ & 4 & $6 \cdot 6233$ & $5 \cdot 36$ & $0 \cdot 5080$ & 0.6785 & 0.4515 & $0 \cdot 0083$ & 0.69 & 182 & $2 \cdot 65$ \\
\hline $\mathrm{Fe}_{3} \mathrm{C}$ & 6 & $8 \cdot 9521$ & $4 \cdot 56$ & 0.5096 & 0.6784 & 0.4521 & 0.0098 & 0.93 & 163 & $1 \cdot 89$ \\
\hline $\mathrm{Fe}_{3} \mathrm{C}$ & 8 & $10 \cdot 0433$ & $4 \cdot 49$ & $0 \cdot 5077$ & 0.6794 & 0.4521 & 0.0147 & 1.05 & 149 & 1.46 \\
\hline $\mathrm{Fe}_{3} \mathrm{C}$ & 10 & $11 \cdot 7536$ & 4.49 & 0.5076 & 0.6795 & 0.4521 & 0.0241 & $1 \cdot 22$ & 128 & 0.82 \\
\hline
\end{tabular}
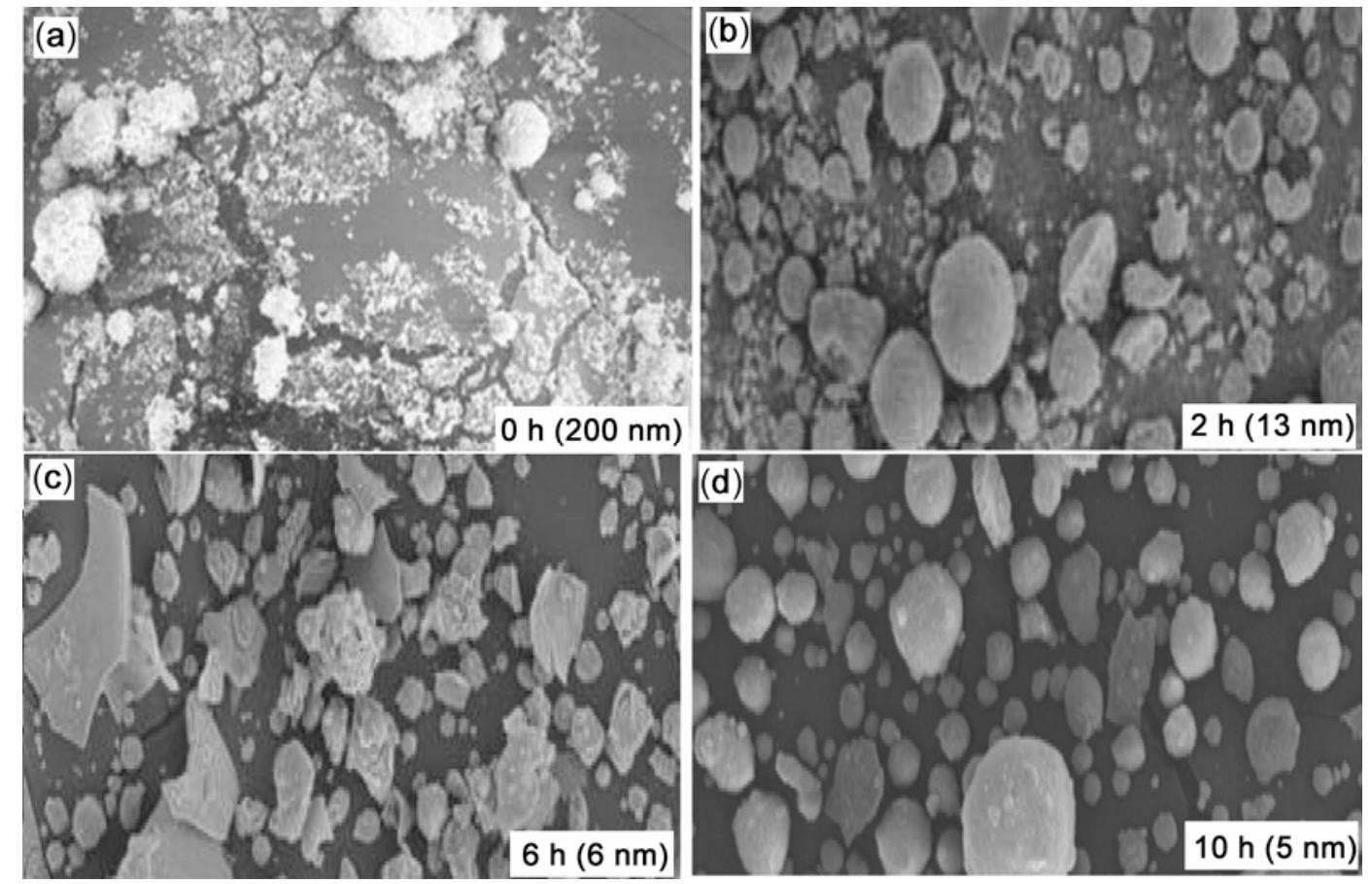

Figure 3. (a-d) Scanning electron microscopy (SEM) morphology of powder particles (a) $0 \mathrm{~h}$, (b) after $2 \mathrm{~h}$, (c) after $6 \mathrm{~h}$ and (d) after $10 \mathrm{~h}$, of milling of $\mathrm{Fe}_{3} \mathrm{C}$ nanoparticle powders.

angle. Based on (7) and (8), the total peak broadening, $B_{\mathrm{r}}$ may be expressed as:

$$
B_{\mathrm{r}}=\frac{k \lambda}{t \cos \theta}+\varepsilon \tan \theta,
$$

which can be written as

$$
B_{\mathrm{r}} \cos \theta=\frac{k \lambda}{t}+\varepsilon \sin \theta .
$$

The plot of $B_{\mathrm{r}} \cos \theta / \lambda$ vs $\sin \theta / \lambda$ is a straight line with slope equal to $\varepsilon$ and hence the particle size $t$ can be estimated from the intercept. Typical Hall-Williamson plot between $B_{\mathrm{r}} \cos \theta / \lambda$ and $\sin \theta / \lambda$ is shown in figure 2 .

The lattice strains were determined from the plot of $B_{\mathrm{r}} \cos \theta / \lambda$ against $\sin \theta / \lambda$ following standard procedures (Kaelble 1967). The measured half-widths were corrected for instrumental broadening with reference to a pure strain-free silicon powder. The variation of particle size with milling time is within the limits of experimental errors. This shows that while the milling is enough to create strains, it affects the particle size to a measurable extent. A typical Hall-Williamson plot is shown in figure 2 for $\mathrm{Fe}_{3} \mathrm{C}$ after milling for $8 \mathrm{~h}$.

\section{Results and discussion}

Figure 1 shows XRD patterns of the $(0 \mathrm{~h})$ mixture (3:1 mol) of $\alpha$-Fe and graphite powders ball milled at room temperature for different durations $0,2,4,6,8$ and $10 \mathrm{~h}$. The values of the lattice parameters, particle size, lattice strain, root mean square amplitudes of vibration, Debye-Waller factors and Debye temperatures of $\mathrm{Fe}_{3} \mathrm{C}$ 
powders, ground for different durations, obtained in the present study are given in table 1 . Figure 2 shows plot of $B_{\mathrm{r}} \cos \theta / \lambda$ vs $\sin \theta / \lambda$ for $\mathrm{Fe}_{3} \mathrm{C}$ after milling for $8 \mathrm{~h}$. Figure $3(\mathrm{a}-\mathrm{d})$ shows the scanning electron microscopy (SEM) morphology of powder particles: (a) $0 \mathrm{~h}$ (200 nm), (b) after $2 \mathrm{~h}(13 \mathrm{~nm})$, (c) after $6 \mathrm{~h}(6 \mathrm{~nm})$ and (d) after $10 \mathrm{~h}$ $(5 \mathrm{~nm})$ of milling of $\mathrm{Fe}_{3} \mathrm{C}$ nanoparticle powders. SEM pictures are good evidence for nanocrystalline state of $\mathrm{Fe}_{3} \mathrm{C}$ nanoparticles by showing agglomerated spherical particles of irregular-shape particles.

Figure 4 shows variation in lattice parameter which indicates that at the early stage of milling, carbon atoms could not be entered into the $\alpha$-Fe matrix and thin graphite layers began to distribute around the $\alpha$-Fe grain boundaries. After $1 \mathrm{~h}$ of milling, carbon atoms started to diffuse through the boundaries of nano $\alpha$-Fe grain and an interstitial $\mathrm{Fe}-\mathrm{C}$ solid solution is formed with a trace amount of carbon. The orthorhombic $\mathrm{Fe}_{3} \mathrm{C}$ phase is formed after $2 \mathrm{~h}$ of milling with lattice parameters very close to the reported value and remains stable up to $8 \mathrm{~h}$ of milling with insignificant changes in lattice parameters are given in table 1 , this is similar to the observations of Pradhan et al (2009).

Although, values of Debye-Waller factor, amplitude of vibration and Debye temperature in the $a$ and $c$ directions

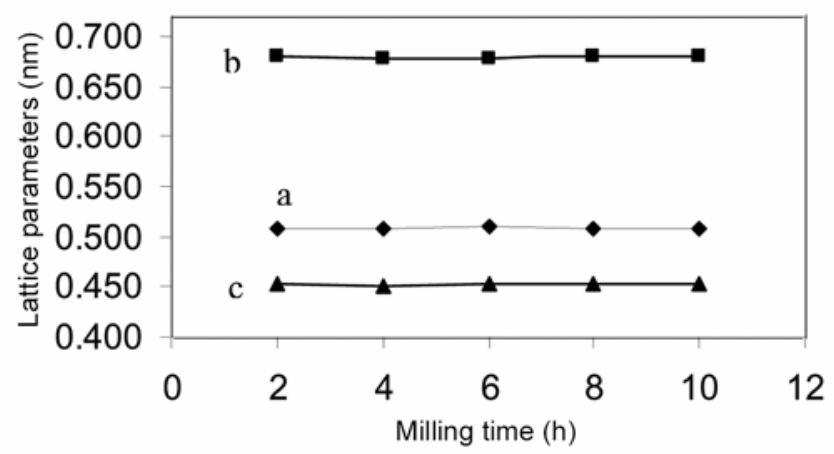

Figure 4. Variation of lattice parameters of $\mathrm{Fe}_{3} \mathrm{C}$ phases in ball-milled mixture of $\alpha$-Fe and graphite (3:1 mol) with increasing milling time.

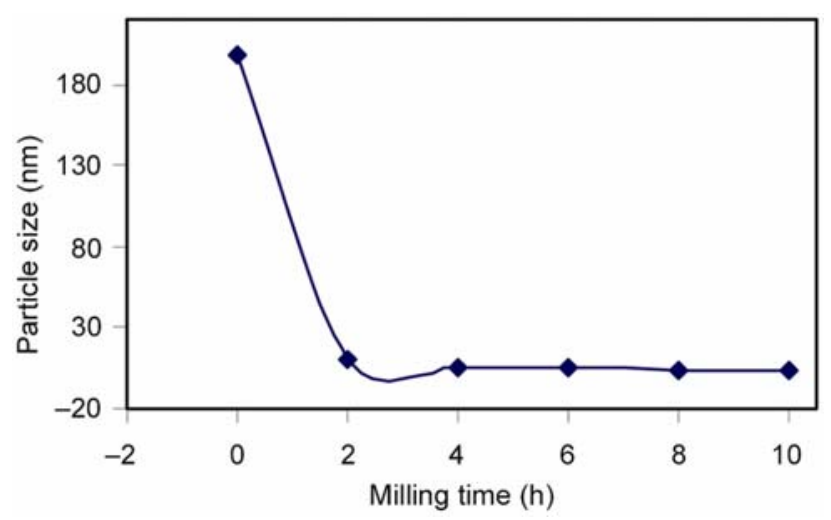

Figure 5. Variation of particle size $(t)$ of $\mathrm{Fe}_{3} \mathrm{C}$ with increasing milling time. have been determined separately, the average values of these quantities are given in table 1 . The objective of the present work is to investigate the strain dependence of Debye-Waller factors.

Figure 5 shows variation of the particle size $(t)$ for different milling times for $\mathrm{Fe}_{3} \mathrm{C}$, particle size decreases with milling time. Figures 6 and 7 show variation of the lattice strain $(\varepsilon)$ and Debye-Waller factor $(B)$ for different milling times for $\mathrm{Fe}_{3} \mathrm{C}$. Both lattice strain and DebyeWaller factor increase with milling time. This is similar to the observations of Inagaki et al (1971, 1973), Sirdeshmuch et al (1993), Gopi Krishna and Sirdeshmukh (1993), Gopi Krishna et al (2010). In the present work, the Debye-Waller factor increases with milling time and lattice strain in a slightly nonlinear fashion.

Figure 8 shows variation between lattice strain $(\varepsilon)$ and Debye-Waller factor $(B)$. An extrapolation of the $B$ vs $\varepsilon$ curve to $\varepsilon=0$ gives the value of Debye-Waller factors of $0 \cdot 24 \AA^{2}$ for $\mathrm{Fe}_{3} \mathrm{C}$. The zero-strain value of Debye-Waller factor is less than the value for the initial sample. Thus, the Debye-Waller factor of $\mathrm{Fe}_{3} \mathrm{C}$ powder sample carries an effect due to lattice strain. While comparing the Debye-Waller factors calculated from the lattice dynamical models with experimental results, Vetelino et al (1972) attributed the difference to inaccuracies in the experimental values caused by neglecting the TDS corrections. The repeated milling of the powder sample leads to lattice distortion which gives rise to microstrains

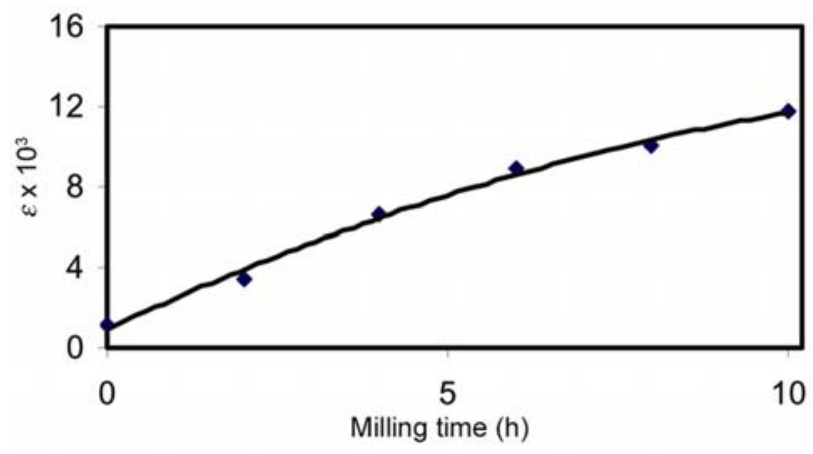

Figure 6. Variation of particle size $(t)$ of $\mathrm{Fe}_{3} \mathrm{C}$ with increasing milling time.

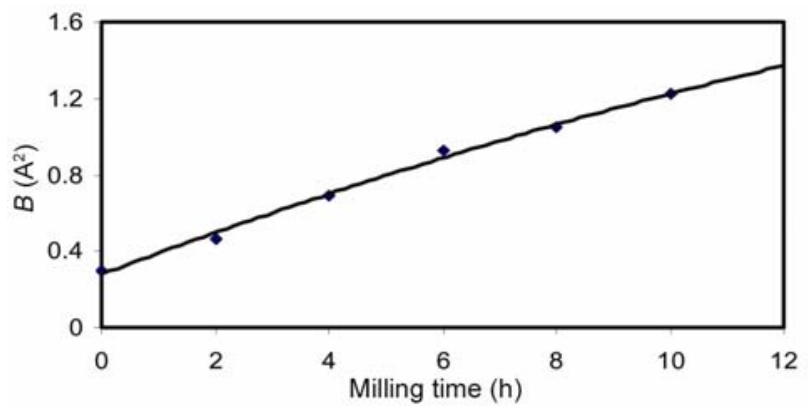

Figure 7. Variation of Debye-Waller factor $(B)$ of $\mathrm{Fe}_{3} \mathrm{C}$ with increasing milling time. 


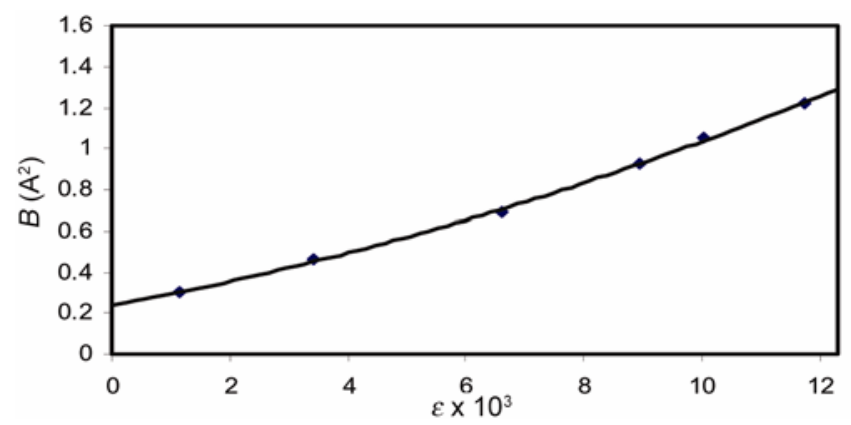

Figure 8. Variation of Debye-Waller factor $(B)$ of $\mathrm{Fe}_{3} \mathrm{C}$ with lattice strain.

in the lattice. These microstrains increase the contribution of static component of Debye-Waller factor. Thus, both lattice strain and observed Debye-Waller factor, which is the sum of static and thermal components, increase with milling time. Thus, whenever Debye-Waller factors are determined from X-ray intensities on powder samples, it is desirable to make an estimate of the lattice strain and if the strain is large, a suitable correction is to be made as in the present study. The Debye temperatures derived from the zero strain values of Debye-Waller factor of $\mathrm{Fe}_{3} \mathrm{C}$ is $289 \mathrm{~K}$.

Glyde (1967) derived the following relation between the energy of vacancy formation $\left(E_{\mathrm{f}}\right)$ and the Debye temperature $(\theta)$ of a solid:

$$
E_{\mathrm{f}}=A(k / \hbar)^{2} \mathrm{M} \theta^{2} a^{2},
$$

where $a$ is the interatomic spacing, $A$ a constant shown to be equal to $1.17 \times 10^{-2}, M$ the molecular weight and $h$ and $k$ are the Plank's and the Boltzmann's constants, respectively. Glyde recommended the use of X-ray based values in (11). The validity of (11) was verified for a number of $f c c, b c c$ and hcp metals (micro- and macroproperties of solids, 2006). Therefore, the X-ray Debye temperatures obtained in the present work have been used to study the variation of vacancy formation energy as a function of lattice strain in $\mathrm{Fe}_{3} \mathrm{C}$. The values of vacancy formation energies are also included in table 1.

\section{Conclusions}

$\mathrm{Fe}_{3} \mathrm{C}$ powder was strained by milling for $10 \mathrm{~h}$. From a study of X-ray diffractograms recorded at different stages of milling, it is observed that milling for $10 \mathrm{~h}$ has systematic effect on the particle size. However, the milling produces lattice strain and also enhances the effective Debye-Waller factor. By an extrapolation of the plot between the Debye-Waller factor and the lattice strain, the zero strain Debye-Waller factors are obtained for $\mathrm{Fe}_{3} \mathrm{C}$. The variation of vacancy formation energy as a function of lattice strain has been studied.

\section{References}

Abid J P, Girault H H and Brevet P F 2001 Chem. Commun. 829

Bharati R, Rehani P, Joshi B, Kirit N Lad and Arun Pratap 2006 Indian J. Pure Appl. Phys 44157

Caer G Le, Bauer-Grosse E, Pianelli A, Bouzy E and Matteazzi P 1990a J. Mater. Sci. 254726

Caer G Le, Matteazzi P, Bauer-Grosse E, Pultz B and Pianelli A 1990b Colloque de Phys. Colloque 51 (suppl. C4) c4

Caer G Le and Matteazzi P 1991 Hyperfine Interact 66309

Calka A 1993 Key Eng. 81-83 17

Chipman D R and Paskin A 1959 J. Appl. Phys. 301938

Colvin V L, Schlamp M C and Alivisatos A P 1994 Nature 370 354

Darugar Q, Qian W and El-Sayed M A 2006 J. Phys. Chem. B110 143

Eastman J A, Cnoi U S, Li S, Yu W and Thompson L J 2001 Appl. Phys. Lett. 78718

Fujiwara H, Yanagida S and Kamat P V 1999 J. Phys. Chem. B103 2589

Glushenkov A M, Zhang H Z and Chen Y 2008 Mater. Lett. 62 4047

Glyde H R 1967 J. Phys Chem. Solids (GB) 282061

Gopi Krishna N and Sirdeshmukh D B 1993 Indian J. Pure Appl. Phys. 31198

Gopi Krishna N et al 2010 Indian J. Phys. 84887

Gopi Krishna N, Sirdeshmukh D B, Rama Rao B, Beandry B J and Gschneidner Jr K A 1986 Indian J. Pure Appl. Phys. 24 324

Inagaki M et al 1971 J. Mater. Sci. 61520

Inagaki M, Furuhashi H, Ozeki T and Naka S 1973 J. Mater. Sci. 8312

International tables for X-ray crystallography 1968 (Birmingham: Kynoch Press) Vol. III

James R W 1967 The optical principles of the diffraction of $X$-rays (London: Bell and Sons)

Kaelble E F 1967 Handbook of X-rays (New York: McGraw Hill)

Kesavan V, Sivanand S P, Chandrasekaran S, Koltypin Y and Gedanken A 1999 Angew. Chem. Int. Ed. 383521

Micro- and Macro-Properties of Solids 2006 Springer Series in Material Science

Nadutov V M, Garamus V M and Rawers J C 2000 Mater. Sci. Forum 721343

Pradhan S K et al 2009 B. J. Alloys Comp. 477127

Shabashov V A, Mukosccv A G and Sagaradze V V 2001 Mater. Sci. Eng. A307 91

Sirdeshmukh D B, Subhadra K G, Hussain K A, Gopi Krishna N and Raghavendra Rao B 1993 Cryst. Res. Technol. 2815

Suryanarayana C 2001 Prog. Mater. Sci. 461

Tanaka T, Ishihara K N and Shingu P H 1992 Met. Trans. 23A 2431

Tokumitsu K 1997 Mater. Sci. Forum 127235

Tokumitsu K and Memoto M U 2001 Mater. Sci. Forum 183 360

Vetelino J F, Gaur S P and Mitra S S 1972 Phys. Rev. B5 2360

Wilson A J C 1949 X-ray optics (London: Methuen) 